Article

\title{
Assessment and Prediction of Climate Risks in Three Major Urban Agglomerations of Eastern China
}

\author{
Jieming Chou ${ }^{1}$, Mingyang Sun ${ }^{1,2, *}$, Wenjie Dong ${ }^{2}$, Weixing Zhao ${ }^{1}$, Jiangnan $\mathrm{Li}^{1}$, Yuanmeng $\mathrm{Li}^{1}$ \\ and Jianyin Zhou ${ }^{3}$ \\ 1 State Key Laboratory of Earth Surface Processes and Resource Ecology, Faculty of Geographical Science, \\ Beijing Normal University, Beijing 100875, China; choujm@bnu.edu.cn (J.C.); \\ 201921051146@mail.bnu.edu.cn (W.Z.); 201921051150@mail.bnu.edu.cn (J.L.); \\ 202021051153@mail.bnu.edu.cn (Y.L.) \\ 2 Atmospheric Science School, Sun Yat-Sen University, Guangzhou 510275, China; dongwj3@mail.sysu.edu.cn \\ 3 College of Meteorology and Oceanography, National University of Defense Technology, \\ Changsha 410073, China; 15165381462@163.com \\ * Correspondence: 201821051163@mail.bnu.edu.cn
}

check for updates

Citation: Chou, J.; Sun, M.; Dong, W.; Zhao, W.; Li, J.; Li, Y.; Zhou, J. Assessment and Prediction of Climate Risks in Three Major Urban Agglomerations of Eastern China. Sustainability 2021, 13, 13037. https:/ / doi.org/10.3390/su132313037

Academic Editors: Xiaodong Yan, Jia Yang, Shaofei Jin and Adriana Del Borghi

Received: 17 August 2021

Accepted: 18 November 2021

Published: 25 November 2021

Publisher's Note: MDPI stays neutral with regard to jurisdictional claims in published maps and institutional affiliations.

Copyright: (c) 2021 by the authors. Licensee MDPI, Basel, Switzerland. This article is an open access article distributed under the terms and conditions of the Creative Commons Attribution (CC BY) license (https:/ / creativecommons.org/licenses/by/ $4.0 /)$.

\begin{abstract}
In the context of global climate change and urban expansion, extreme urban weather events occur frequently and cause significant social problems and economic losses. To study the climate risks associated with rapid urbanization in the global context of climate change, the vulnerability degree of urban agglomeration is constructed by the Grey Model $(\mathrm{GM}(1,1))$. Based on the sixth phase of the Coupled Model Intercomparison Project (CMIP6) data sets SSP1-2.6, SSP2-4.5, and SSP5-8.5, drought, heat wave, and flood hazards under different emission scenarios are calculated. The vulnerability degree of the urban agglomeration and the climate change hazard were input into the climate change risk assessment model to evaluate future climate change risk. The analysis results show regional differences, with the Beijing-Tianjin-Hebei urban agglomeration having good urban resilience, the Yangtze River Delta urban agglomeration having slightly higher overall risk, and the Pearl River Delta urban agglomeration having the highest relative risk overall. On the whole, the higher the emission intensity is, the greater the risk of climate change to each urban agglomeration under different emission scenarios.
\end{abstract}

Keywords: climate change; urban agglomeration; drought; heat wave; flood; risk assessment; GM $(1,1)$

\section{Introduction}

The global climate system has significantly warmed in the past century, with the global average surface temperature increasing by approximately $0.9{ }^{\circ} \mathrm{C}$ from 1900 to 2018 [1]. China has a high incidence of extreme weather events. In the context of global warming and high incidence of extreme weather events, this paper studies the inherent relationship between the high incidence of extreme weather events and climate warming. The multiscenario risk assessment of drought, high temperature, heat wave, and flood under climate change and urban expansion is a hot topic in urban sustainable development. In this paper, we predict the risks of drought, heat wave, and flood during the next 30 years based on the BCC-CSM2-MR data sets SSP1-2.6, SSP2-4.5, and SSP5-8.5. This paper focuses on the climate change risks to the three major urban agglomerations: Beijing-Tianjin-Hebei, Yangtze River Delta, and Pearl River Delta in China, which is significant for the study of climate change risks to large urban agglomerations in other countries.

In their research, domestic and foreign scholars have carried out many studies on the responses of urban agglomerations to climate change. According to the Intergovernmental Panel on Climate Change (IPCC)'s Fifth Assessment Report (AR5) [2], climate change risk is quantified as a function of hazard, exposure, and vulnerability. However, there are two shortcomings at present. First, previous climate change risk studies focused on the 
risk of a certain disaster in a particular city; however, in the context of climate change, more attention should be paid to the risk of multiple disaster types and complex disasterbearing bodies, and the evolution characteristics of each disaster risk in time and space are also worth examining [3-5]. Second, a large number of studies have focused more on internal factors and climate risks such as hazards, exposure, and vulnerability [6,7], while ignoring the risk forcing of external factors such as urbanization and climate change [8]. According to the United Nations Strategy for Disaster Reduction (ISDR), climate change and urbanization are the two main factors that make human beings more vulnerable to disasters [9]. Though the AR5 delineates exposure as a separate component of the risk, in this study, we included exposure as an integral part of the vulnerability. Therefore, the vulnerability degree of an urban agglomeration is defined based on the comprehensive consideration of exposure and vulnerability. The concept of vulnerability involves different disciplines and professional fields such as sociology, economics, and disaster management. In this paper, the vulnerability degree of an urban agglomeration refers to the degree to which the social system affected by climate pressure and the urbanization process has been damaged because of its own sensitivity and vulnerability. Hazard, as the core of climate change risk, is used to identify the location and intensity of weather events such as drought, heat wave, and floods [10]. Based on the vulnerability of urban agglomerations and the risk of climate change, this paper establishes a basic model for climate change risk assessment.

The three major urban agglomerations along the east coast of China are important engines of regional economic and social development; however, they are also vulnerable to climate change. Edward pointed out that the impacts of sea level rise and extreme weather, such as heat waves and floods, have seriously affected the economic life of coastal cities, and it is very important to adapt to the impact of climate change on coastal cities through economic construction and emergency response [11]. Global warming, melting glaciers, and the rising sea level have a huge impact on coastal cities, making them more vulnerable to rainstorms and floods $[12,13]$. With the acceleration of urbanization and the impact of global warming, the frequency and intensity of extreme events such as droughts, heat waves, and floods increase, which has a huge impact on the power supply, water supply, and transportation in urban infrastructure $[14,15]$. In this paper, the vulnerability of urban agglomerations and the hazard of climate change are input into the climate change risk assessment model to comprehensively estimate the future climate change risks to the three major urban agglomerations in eastern China. The combination of natural ecosystems and socioeconomic systems can help to control the degree and probability of the impact of climate change on the three major urban agglomerations. This can provide a scientific basis for disaster prevention and mitigation, and emergency response in cities.

\section{Research Area}

With the acceleration of urbanization, population and industries have been concentrated in the eastern coastal areas of China, forming three city clusters: Beijing-TianjinHebei, Yangtze River Delta, and Pearl River Delta [16]. These generally have a large population density and rapid economic development. At the same time, a nationally important transport hub exists around the port and the nuclear power plant, which means that the degree of exposure and vulnerability of these urban agglomerations to disasters and large economic losses is bigger than other cities. Therefore, eastern China's urban agglomeration, with the highest level of national economic contribution, has become a potential large-scale disaster-bearing body.

In the eastern coastal area with the largest population density distribution and the highest level of national economic development, the three urban agglomerations of Beijing, Tianjin, and Hebei, the Yangtze River Delta, and the Pearl River Delta are the most mature and competitive urban agglomerations in China [17]. Table 1 shows their location information and basic characteristics while Figure 1 shows their geographical distribution and the prefecture-level cities they contain. With the rapid growth of China's economy and the continuous evolution of its cities, urban agglomeration has gradually become the symbol of 
a higher stage of urban development. It can strengthen the interconnection among various cities, promote the process of economic integration, and encourage the rapid growth of the regional economy. On the other hand, because of the high concentration of resources, environment, ecosystem, and social economy in urban agglomerations, they have a stronger impact on the exposure, sensitivity, and vulnerability to extreme weather events, and the risk to them from climate change is significant. Therefore, studying the climate, economic change characteristics, and development laws of these three urban agglomerations is of great significance for promoting their social development process as the main bodies in China and the balanced and stable development of various regions.

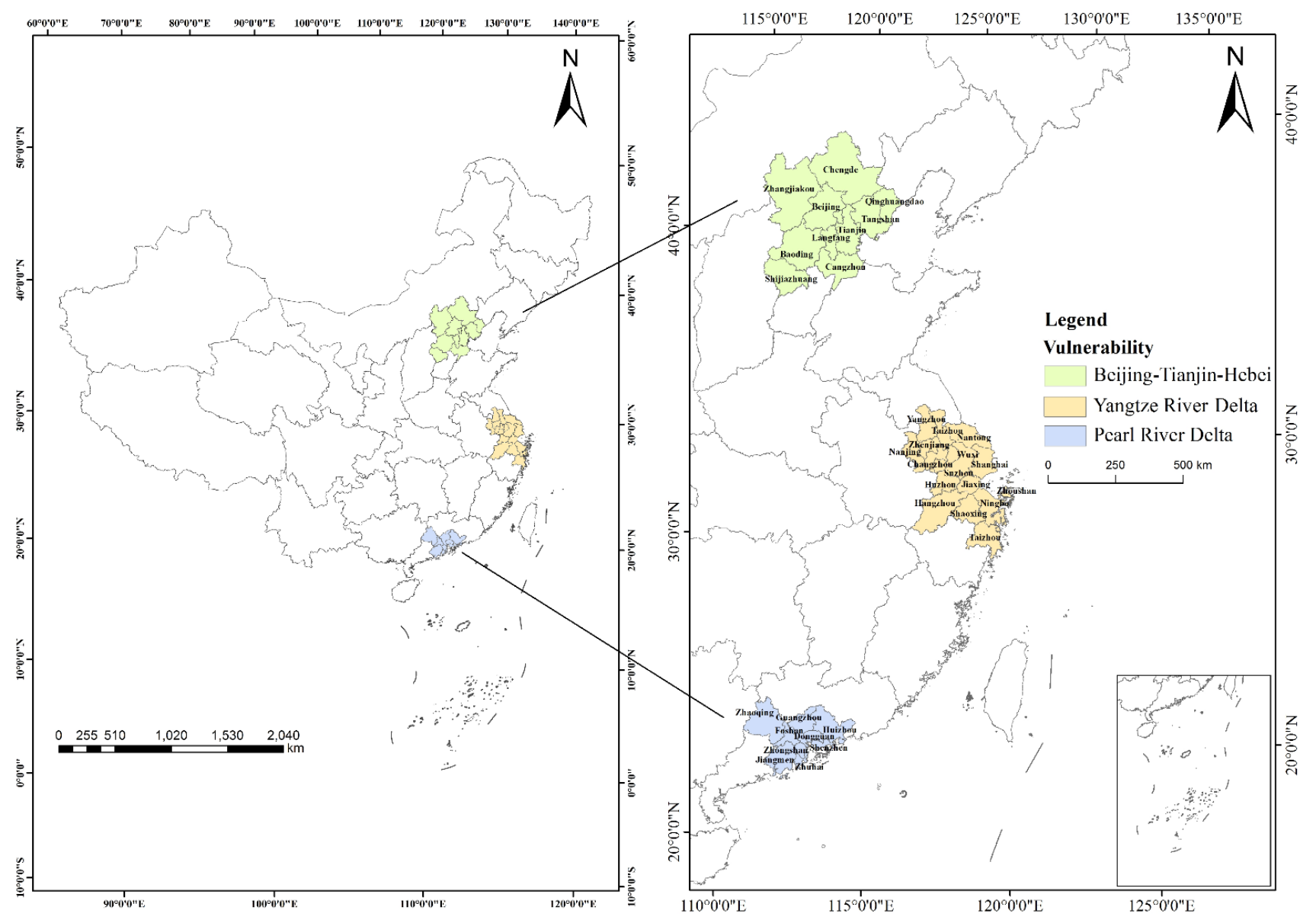

Figure 1. Distribution and names of the three major urban agglomerations in China.

Table 1. Three urban agglomerations in China and their basic characteristics.

\begin{tabular}{|c|c|c|c|}
\hline Name & Range & $\begin{array}{l}\text { Geographical } \\
\text { Position }\end{array}$ & Basic Characteristics \\
\hline $\begin{array}{l}\text { Beijing-Tianjin- } \\
\text { Hebei Urban } \\
\text { Agglomeration }\end{array}$ & $\begin{array}{l}\text { With Beijing, Tianjin } \\
\text { as the center, } \\
\text { including } \\
\text { Shijiazhuang, } \\
\text { Baoding, } \\
\text { Zhangiakou, } \\
\text { Tangshan, } \\
\text { Qinhuangdao, } \\
\text { Langfang, Cangzhou, } \\
\text { Chengde. }\end{array}$ & $\begin{array}{l}\text { Located north of the } \\
\text { North China Plain, } \\
\text { the center of } \\
\text { Northeast Asia in } \\
\text { China, bordering on } \\
\text { Bohai Sea. }\end{array}$ & $\begin{array}{l}\text { It covers an area of } \\
183,088 \mathrm{~km}^{2}, \text { has a } \\
\text { population of } 90.09 \\
\text { million, and a GDP of } \\
\text { CNY } 7.70 \text { trillion. It is the } \\
\text { capital economic circle of } \\
\text { China and the largest and } \\
\text { most dynamic area. }\end{array}$ \\
\hline
\end{tabular}


Table 1. Cont.

\begin{tabular}{|c|c|c|c|}
\hline Name & Range & $\begin{array}{c}\text { Geographical } \\
\text { Position }\end{array}$ & Basic Characteristics \\
\hline $\begin{array}{l}\text { Yangtze River } \\
\text { Delta Urban } \\
\text { Agglomeration }\end{array}$ & $\begin{array}{l}\text { With Shanghai and } \\
\text { Nanjing as the center, } \\
\text { including Suzhou, } \\
\text { Wuxi, Changzhou, } \\
\text { Zhengjiang, Nantong, } \\
\text { Yangzhou, Taizhou } \\
\text { (in Jiangsu), } \\
\text { Hangzhou, Ningbo, } \\
\text { Jiaxing, Huzhou, } \\
\text { Shaoxing, Zhoushan } \\
\text { and Taizhou (in } \\
\text { Zhejiang). }\end{array}$ & $\begin{array}{l}\text { Located in the lower } \\
\text { reaches of the } \\
\text { Yangtze River, } \\
\text { bordering on the } \\
\text { Yellow Sea and the } \\
\text { East China Sea, with } \\
\text { many ports, it is an } \\
\text { impact plain formed } \\
\text { before the Yangtze } \\
\text { River enters the sea. }\end{array}$ & $\begin{array}{l}\text { The area is } 132,065 \mathrm{~km}^{2} \text {, } \\
\text { with a population of } \\
11.47 \text { million and a GDP } \\
\text { of CNY } 15.02 \text { trillion. It is } \\
\text { an important zone } \\
\text { between the "one belt, } \\
\text { one road" and the } \\
\text { "Yangtze River Economic } \\
\text { Belt" and is the most } \\
\text { densely distributed area } \\
\text { and largest economic } \\
\text { zone in China. }\end{array}$ \\
\hline $\begin{array}{c}\text { Pearl River } \\
\text { Delta Urban } \\
\text { Agglomeration }\end{array}$ & $\begin{array}{l}\text { With Guangzhou, } \\
\text { Shenzhen as the } \\
\text { center, including } \\
\text { Zhuhai, Foshan, } \\
\text { Jiangmen, Dongguan, } \\
\text { Zhongshan, Huizhou, } \\
\text { Zhaoqing. }\end{array}$ & $\begin{array}{l}\text { It is located at the } \\
\text { Pearl River estuary in } \\
\text { the south central part } \\
\text { of Guangdong } \\
\text { Province. It is } \\
\text { adjacent to Hong } \\
\text { Kong and Macao. }\end{array}$ & $\begin{array}{l}\text { It has an area of } 55,061 \\
\mathrm{~km}^{2} \text {, population of } 0.63 \\
\text { million and a GDP of } \\
\text { CNY } 8.10 \text { trillion. As one } \\
\text { of the most dynamic } \\
\text { economic groups in the } \\
\text { Asia Pacific region, it is } \\
\text { also the gateway for the } \\
\text { southern region to open } \\
\text { up to the outside world. }\end{array}$ \\
\hline
\end{tabular}

Note: the data are calculated according to the China Statistical Yearbook 2018 and the statistical yearbook of relevant provinces (cities) for 2018.

\section{Data and Methods}

3.1. Data

Data Sources

The historical climate data were taken from the National Meteorological Information Center of China (http: / / data.cma.cn (accessed on 22 November 2021)). The meteorological stations of Beijing-Tianjin-Hebei, Yangtze River Delta, and Pearl River Delta were selected. To maintain the homogeneity of the data, this paper selected the daily average temperature (unit: ${ }^{\circ} \mathrm{C}$ ), daily average precipitation (unit: $\mathrm{mm}$ ), daily maximum temperature (unit: ${ }^{\circ} \mathrm{C}$ ), monthly average temperature (unit: ${ }^{\circ} \mathrm{C}$ ), and relative humidity (unit: \%) from 1981 to 2019.

The social and economic data used in this paper were taken from the China National Statistical Center (http: / / www.bjstats.gov.cn (accessed on 22 November 2021)). The China Statistical Yearbook provided the GDP per capita (unit: yuan), permanent population (unit: thousand), urban population (unit: thousand), urban area (unit: thousand ha), total area (unit: thousand ha), and proportion of primary industry in the GDP (unit: \%) of the Beijing-Tianjin-Hebei, Yangtze River Delta, and Pearl River Delta urban regions from 1981 to 2019.

The future climate scenario data came from the BCC-CSM2-MR climate model of the sixth phase of the Coupled Model Intercomparison Project (CMIP6). The model uses 320 (longitude) * 160 (latitude) grid points to cover the globe. It is newly developed by the National Climate Center. The ability of the BCC-CSM2-MR climate model to simulate the climate mean state and global warming trend, quasi-biennial oscillation $(\mathrm{QBO})$, tropical intraseasonal oscillation (MJO), and diurnal variation in precipitation for the 20th century has significantly improved [18]. In this paper, daily temperature (unit: ${ }^{\circ} \mathrm{C}$ ), daily precipitation (unit: $\mathrm{mm}$ ), and daily relative humidity (\%) from 2020 to 2050 were selected. Three emission scenarios, SSP1-2.6, SSP2-4.5, and SSP5-8.5, were selected for the climate prediction experiment (https:/ / esgf-node.llnl.gov/search/cmip6/ (accessed on 22 November 2021)). Table 2 shows the main characteristics of various representative concentration paths. 
Table 2. Main characteristics of various representative concentration paths.

\begin{tabular}{cccc}
\hline Scenario Component & SSP1-2.6 & SSP2-4.5 & SSP5-8.5 \\
\hline Radiative forcing & $2.6 \mathrm{Wm}^{-2}$ & $4.5 \mathrm{Wm}^{-2}$ & $8.5 \mathrm{Wm}^{-2}$ \\
\hline Greenhouse gas emission & Very low & Medium-low & High \\
\hline
\end{tabular}

\subsection{Method}

In this paper, the AHP is used to construct the vulnerability assessment system of the three major urban agglomerations. Using an integrated meteorological drought index, heat wave index, and flood index, the risk to the three urban agglomerations of meteorological disasters was evaluated. In this paper, the vulnerability of urban agglomerations and the hazard of climate change were input into the climate change risk assessment model to comprehensively estimate the future climate change risk to the three major urban agglomerations in eastern China. Figure 2 shows the flow chart of climate change risk assessment. The specific methods are as follows:

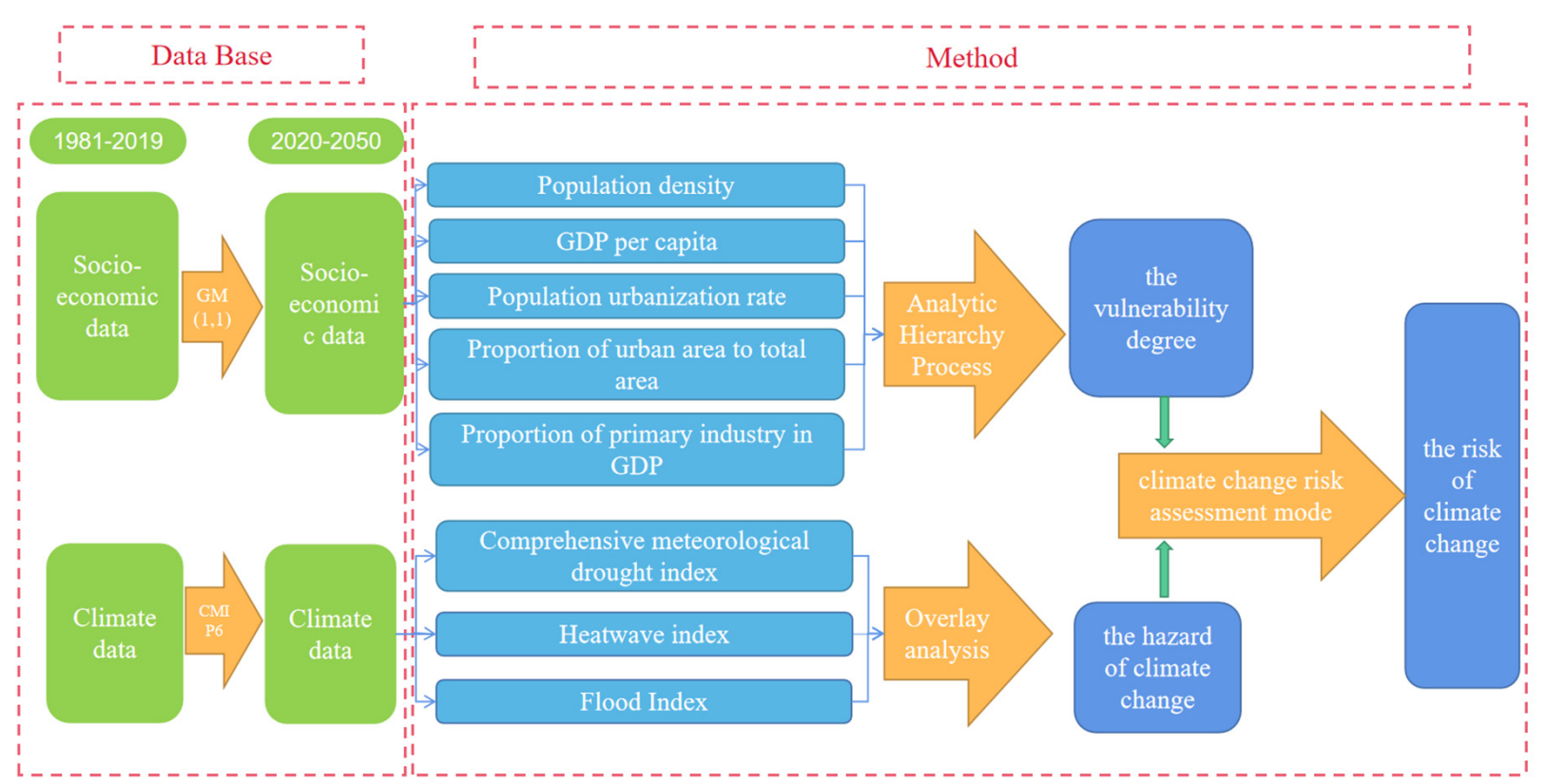

Figure 2. Flow chart of climate change risk assessment.

\subsubsection{Grey System Model GM $(1,1)$}

The GM $(1,1)$ model constructed by Deng is a method to solve the lack of data and shortage of information, and create a fuzzy long-term description of the law of development of things [19]. Socioeconomic data include the GDP per capita (unit: yuan), permanent population (unit: thousand), urban population (unit: thousand), urban area (unit: thousand ha), total area (unit: thousand ha), and proportion of primary industry in the GDP (unit: \%). As the data are affected by many factors, it was difficult to use a single linear trend for effective prediction. Therefore, this paper used the GM $(1,1)$ to predict the socioeconomic data from 2020 to 2050 . The GM $(1,1)$ is a method to solve the problems of insufficient data, poor information, and high fitting accuracy [20]. The GM $(1,1)$ uses differential equations to fully explore the essence of the system. This theory takes a small amount of irregular raw data as samples and organizes them in a regular series after data accumulation [21]. Then, a reduction process is performed to obtain the forecasted data for the target year. 
Let the original variable be $X^{(0)}=\left\{X^{(0)}(i), i=1,2, \ldots, n\right\}, X^{(0)}(i) \geq 0$. By adding $\mathrm{X}^{(0)}$, we obtain the following results:

$$
\mathrm{X}^{(1)}=\left\{\mathrm{X}^{(1)}(k), \quad k=1, \quad 2, \quad \ldots, \quad \mathrm{n}\right\}
$$

where

$$
X^{(1)}(k)=\sum_{i=1}^{k} X^{(0)}(\mathrm{i})=X^{(1)}(k-1)+X^{(0)}(k)
$$

The following differential equations were established to create the GM $(1,1)$ model:

$$
\frac{d X^{(1)}}{d t}+a X^{(1)}=\mathrm{u}
$$

\subsubsection{Analytic Hierarchy Process}

The AHP is a decision analysis method that decomposes factors related to decisions and conducts qualitative and quantitative analyses [22]. When facing a complex problem, it conducts a deeper analysis of its internal influencing factors and uses less quantitative information to mathematically carry out the decision-making process. This method is widely used at present [23]. Its basic principle is to decompose the decision-making process into different hierarchical structures. Experts assign quantitative scores according to the relative importance of each element to construct a judgment matrix A.

The calculation results of the matrix must pass a consistency test to avoid the contradictory situation where $A$ is more important than $B, B$ is more important than $C$, and $C$ is more important than A for each internal element [24]. CI is a consistency indicator. Smaller values of $\mathrm{CI}$ indicate greater consistency. RI is a random consistency index, which is related to the order of the judgment matrix. In general, the greater the order of the matrix, the greater the possibility of random consistency deviation.

The random consistency ratio further evaluates the judgment matrix.

$$
\mathrm{CR}=\mathrm{CI} / \mathrm{RI}
$$

When $\mathrm{CR}$ is less than 0.1 , matrix $\mathrm{A}$ is considered to have satisfactory consistency; otherwise, the judgment matrix must be revised.

To better evaluate the vulnerability degree of urban agglomeration, this paper standardized the above data and used the AHP to determine the weight of the GDP per unit area, the population density, the population urbanization rate, the proportion of urban area in total area, and the proportion of primary industry in the GDP (see Appendix A).

\subsubsection{Vulnerability of the Carrier}

This paper selected the GDP per unit area, the population density, the population urbanization rate, the proportion of urban area in the total area, and the proportion of primary industry in the GDP as the indicators of the vulnerability of the carrier.

The index analysis model of the vulnerability degree evaluation index system is as follows:

$$
Z=\Sigma U_{i} W_{i}
$$

where $Z$ is the vulnerability degree of each coastal urban area; this paper divided the GDP per unit area, the population density, the population urbanization rate, the proportion of urban area in total area, and the proportion of primary industry in the GDP into five grades: $U_{i}$ is the grade of the $i$-th index in an urban area; $W_{i}$ is the weight of index $i$, which was obtained with the AHP (see Table 3). 
Table 3. Analytic hierarchy process.

\begin{tabular}{cccccc}
\hline & $\begin{array}{c}\text { Population Density } \\
\text { (People/ } \mathbf{k m}^{2} \text { ) }\end{array}$ & $\begin{array}{c}\text { GDP per Capita } \\
\text { (Thousand Yuan) }\end{array}$ & $\begin{array}{c}\text { Population } \\
\text { Urbanization rate }\end{array}$ & $\begin{array}{c}\text { Proportion of Urban } \\
\text { Area to Total Area }\end{array}$ & $\begin{array}{c}\text { Proportion of Primary } \\
\text { Industry in GDP }\end{array}$ \\
\hline 1 & $<200$ & $<20$ & $<0.5$ & $<0.15$ & $<6.4$ \\
2 & $200-500$ & $20-50$ & $0.5-0.6$ & $0.15-0.30$ & $6.4-12.7$ \\
3 & $500-1000$ & $50-80$ & $0.6-0.7$ & $0.30-0.50$ & $12.7-17.7$ \\
4 & $1000-1500$ & $80-100$ & $0.7-0.8$ & $0.50-0.70$ & $17.7-28.2$ \\
5 & $>1500$ & $>100$ & $>0.8$ & $>0.7$ & $>28.2$ \\
\hline weight & 0.31 & 0.29 & 0.12 & 0.13 & 0.15 \\
\hline
\end{tabular}

See Appendix A for the calculation process.

\subsubsection{Calculation of Meteorological Risk Index}

In this paper, the hazard of climate change refers to drought, heat wave, and flood. The comprehensive meteorological drought index, heat wave index, and flood index were calculated to describe the hazard degrees of the three meteorological disasters. The following are the calculation methods of the three indexes.

\section{A: Comprehensive Meteorological Drought Index}

The comprehensive meteorological drought index $(C I)$ was used to analyze the spatiotemporal characteristics of drought in the three urban agglomerations in eastern China [25]. The smaller the value of the $C I$, the greater the absolute value, indicating that the drought in this region is more serious. It reflects the drought situation of a certain region on a long time scale and has been widely used since it was first proposed [26]. The comprehensive meteorological drought index $(C I)$ is calculated by the following formula:

$$
C I=a Z_{30}+b Z_{90}+c M_{30}
$$

where: $a$ is $0.4 ; b$ is $0.4 ; c$ is $0.8 . Z_{30}$ and $Z_{90}$ are the standardized precipitation index (SPI) values in the last 30 and 90 days, respectively, and $M_{30}$ is the relative humidity index in the last 30 days. The specific calculation process has been detailed in the literature [27].

\section{B: Heat Wave Index}

The heat wave index reflects the duration of extremely high temperatures because China occupies a vast area with a large regional climate difference, and its tolerance to high temperatures is variable [28]. In this paper, the local daily meteorological data from May to September from 1981 to 2019 were used to first calculate the torridity index of the samples whose maximum temperature was greater than $33^{\circ} \mathrm{C}$. After sorting the torridity index sequence into ascending order, the median was selected as the local critical value of torridity, which represents the comfort level of the human body with respect to the meteorological environment [29].

The torridity index $\left(E_{r}\right)$ is calculated by the following formula:

$$
\begin{aligned}
& \text { When } R H \leq 60 \%, E_{r}=1.8 \times T_{a}-0.55 \times\left(1.8 \times T_{a}-26\right) \times(1-0.6)+32 \\
& \text { When } R H>60 \%, E_{r}=1.8 \times T_{a}-0.55 \times\left(1.8 \times T_{a}-26\right) \times(1-R H)+32
\end{aligned}
$$

where $T_{a}$ represents ambient temperature $/{ }^{\circ} \mathrm{C}$ and $R H$ stands for average daily relative humidity $/ \%$.

After calculating the torridity index, the heat wave index $(\mathrm{Hi})$ is calculated as follows:

$$
H I=1.2 \times\left(E r-E r^{\prime}\right)+0.35 \sum_{i=1}^{N-1} 1 / n d_{i}\left(E r_{i}-E r^{\prime}\right)+0.15 \sum_{i=1}^{N-1} \frac{1}{n d_{i}}+1
$$


where $i$ is the previous day, and the number of days from day $i$ before the day is $n d_{i}$. The torridity index of the day is $E r$, the critical value of torridity is $E r^{\prime}$, and the torridity index of day i before the day is $E r_{i}$.

\section{C: Flood Index}

The flood index $(F I)$ is based on the cumulative precipitation of a region for 3 consecutive days.

$$
F I=\sum_{i=N}^{N+2} P_{i}
$$

where $P_{i}$ is the precipitation on day $\mathrm{i}$ of a city, and $P_{i}$ is in units of $\mathrm{mm}$.

\subsubsection{Climate Change Risk Assessment Model}

Disaster risk generally considers disaster-causing factors and the disaster-bearing body:

$$
\text { Risk }=\text { Hazard } * \text { Vulnerability }
$$

Disaster risk is equal to the product of disaster hazard and vulnerability of the disasterbearing body [30].

This paper improved the disaster risk model to better describe the impact of climate change and urbanization on assessing the climate change risk.

$$
\mathrm{R}=(\mathrm{D}+\mathrm{H}+\mathrm{F}) * \mathrm{~V}
$$

where $\mathrm{R}$ represents the risk of climate change, $\mathrm{D}$ represents the drought hazard, $\mathrm{H}$ represents the heat wave hazard, F represents the flood hazard, and V represents the vulnerability of urban agglomerations.

\section{Results and Discussion}

\subsection{Vulnerability of Three Urban Agglomerations from 1981 to 2019}

China's three major urban agglomerations are all located in the eastern coastal areas. Most of the country's infrastructure was built in the 21st century. Science and technology are the fundamental driving forces for us to improve the level of disaster tolerance. With meteorological risk and disaster occurrence rising yearly, it is very important to evaluate the climate change tolerance of these rapidly developing urban agglomerations.

This paper considered the three major urban agglomerations in eastern China as the research area and their social conditions as the research object to analyze through the following indicators:

According to the theory of natural disaster systems, the above five indicators were selected and stratified [31]. To better evaluate vulnerability, this paper standardized the above data and used the AHP to determine the weight of the five elements in the evaluation of the vulnerability degree of the carrier (see Table 3).

The vulnerability degree was divided into five registration regions according to the values of each vulnerability degree: the lowest vulnerability, low vulnerability, medium vulnerability, high vulnerability, and the highest vulnerability, and the spatial description and expression were mapped, as shown in Figure 3.

Figure 3 shows that the vulnerability degree of each urban agglomeration was relatively low in 1985, then increased over time. The main reason is that the three major urban agglomerations were expanding with the continuous advancement of urbanization and inward population migration. As a major component of the natural ecosystem, human beings are in a fragile and vulnerable state. The rapidly increasing population density increases the vulnerability of urban agglomerations. In addition, it can be seen from the figure that the high vulnerability in 2015 was mainly concentrated in the first-tier cities Beijing, Tianjin, Nanjing, Wuxi, Suzhou, Shanghai, Foshan, Guangzhou, Shenzhen, and Dongguan. In the vulnerability assessment of urban agglomerations, a higher GDP means 
higher economic benefits for the city and higher risks to the city when meteorological disasters strike. On the whole, among the three major urban agglomerations in 2015, the most vulnerable urban area was the Yangtze River Delta, which is also currently the city agglomeration with the largest GDP output among the three major urban agglomerations, contributing approximately one-fifth of the national GDP. Compared with the Yangtze River Delta and the Pearl River Delta, the vulnerability degree of the Beijing-Tianjin-Hebei urban agglomeration was generally lower, which was consistent with its economic development in recent years. During this time, the economic development gap between Beijing and Tianjin, and other cities in the Beijing-Tianjin-Hebei region has become increasingly obvious. There is a significant gap between the rich and the poor in the Beijing-Tianjin-Hebei urban agglomeration.
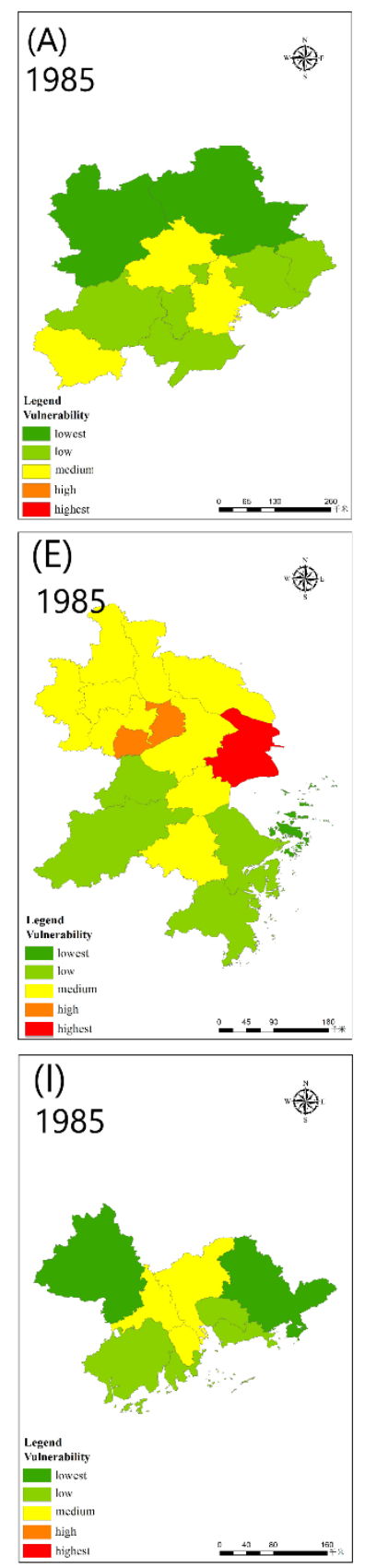
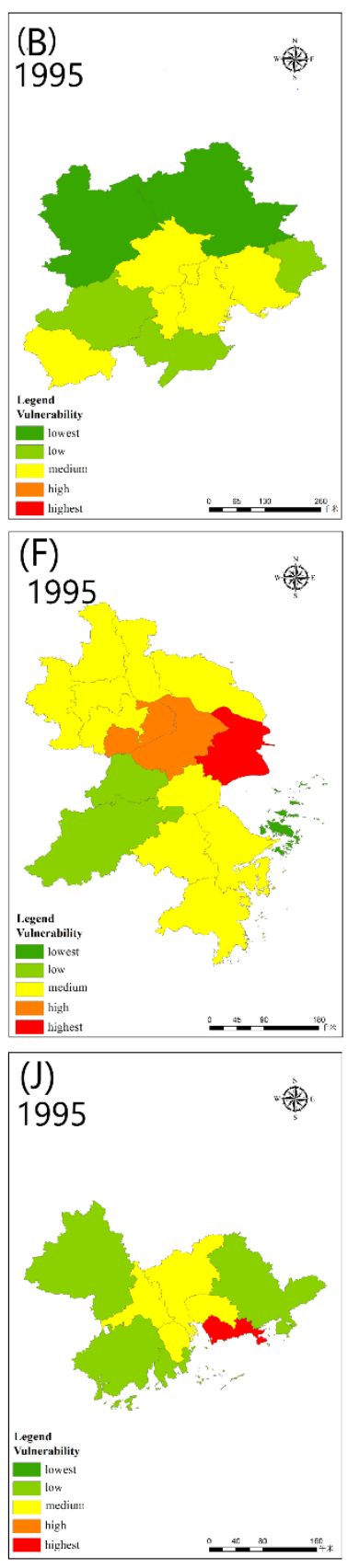
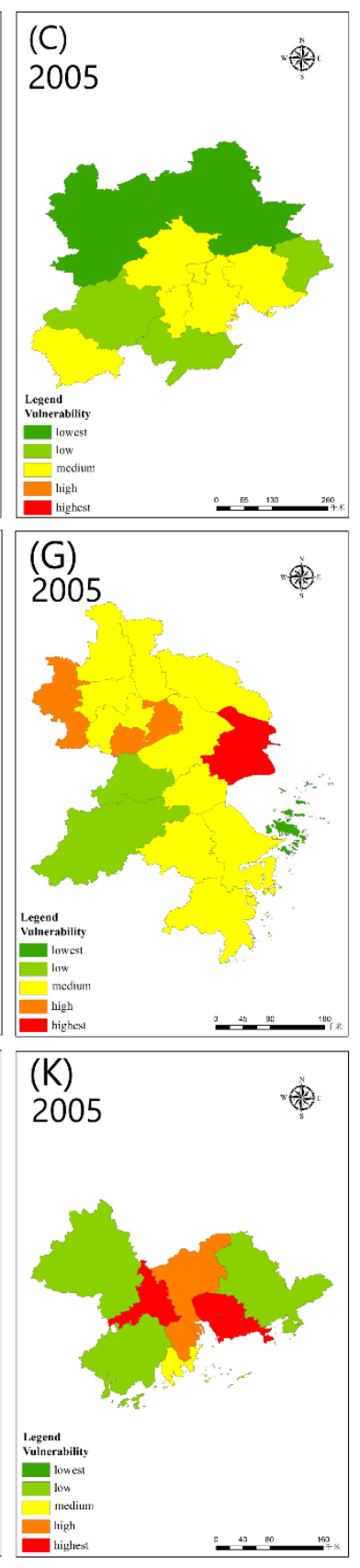
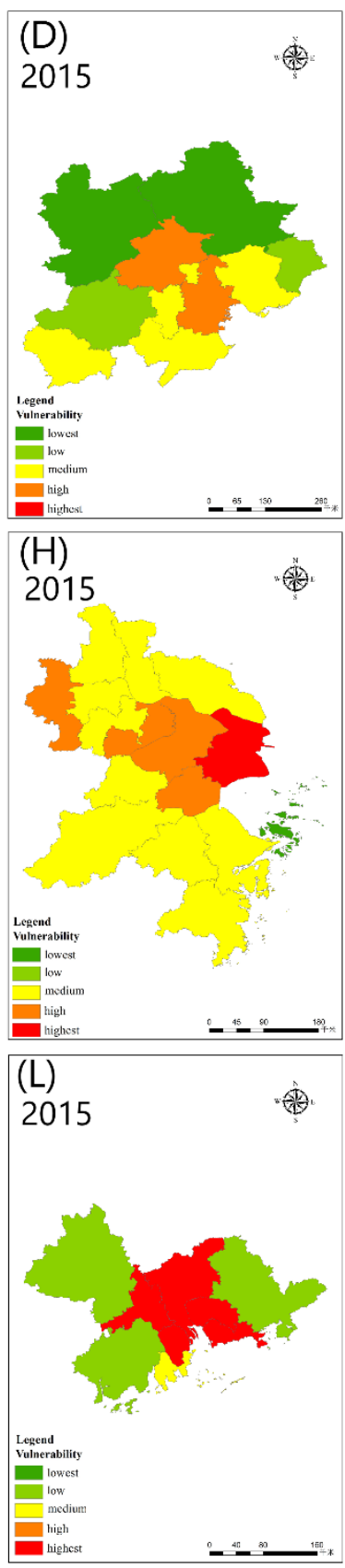

Figure 3. Evolution of the spatial pattern of the vulnerability degree of the three urban agglomerations in 1985, 1995, 2005, and 2015 (A-D): Beijing-Tianjin-Hebei; (E-H): The Yangtze River Delta; (I-L): Pearl River Delta. 


\subsection{Risk of Meteorological Disasters in Urban Agglomerations from 1981 to 2019}

\subsubsection{Comprehensive Meteorological Drought Index}

Figure 4 shows the geographical distribution of the annual average drought index in the three eastern coastal urban agglomerations. The smaller the $C I$ value is, the drier the region is. From this, we can see that the Beijing-Tianjin-Hebei region generally presented the characteristics of wetness in the west and dryness in the east [32]. The drought index in the Yangtze River Delta region gradually decreased from south to north, with the drought degree in the northern part notably stronger than in the southern part. The reason for this is that, in the plum rain season, the western Pacific Ocean brings much water vapor from south to north, and the Yangtze River Delta urban agglomeration maintains steady and sustained precipitation. The distribution of the drought index in the Pearl River Delta region was lower in the northwest and higher in the southeast. The reason for this may be that the West Pacific subtropical high brought much water vapor and precipitation to the southeast of the Pearl River Delta, therefore the drought index in the southeast direction was greater.
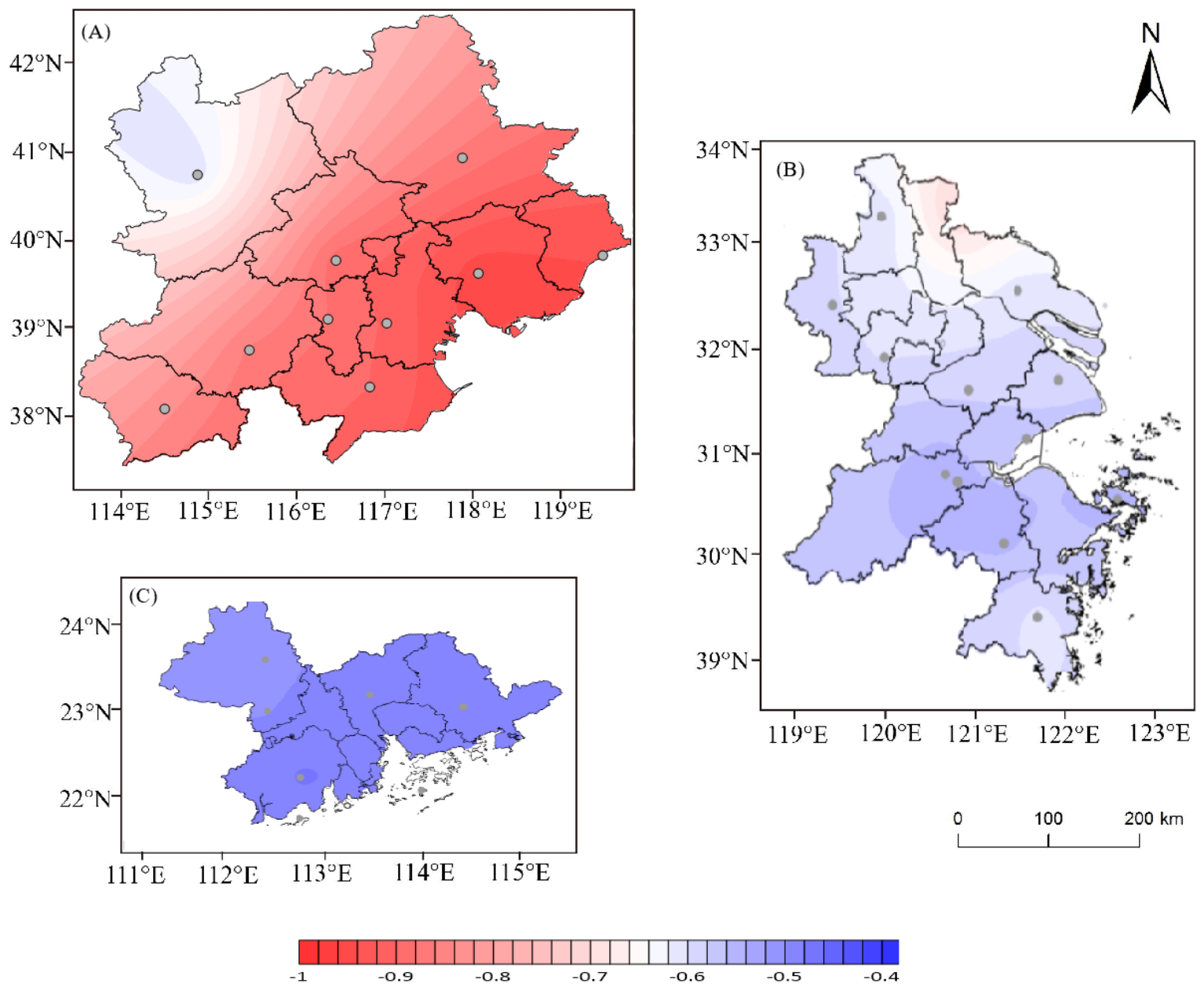

Figure 4. Geographical distribution of the annual mean comprehensive meteorological drought index in the three urban agglomerations (A): Beijing-Tianjin-Hebei; (B): Yangtze River Delta; (C): Pearl River Delta.

Overall, the western part of the Beijing-Tianjin-Hebei region is located on the North China Plain, and the integrated meteorological drought index CI was minimal. The BeijingTianjin-Hebei region was the driest among the three major coastal urban agglomerations in eastern China, followed by the Yangtze River Delta and the Pearl River Delta, which had the lowest drought index. Located in the southeastern coastal area of China, the Pearl River Delta urban agglomeration is closer to the ocean and has abundant water vapor. From 
its definition, we can see that the factors affecting the strength of the drought index were precipitation and potential evapotranspiration. Therefore, the drought index of southern coastal cities was larger than that of northern inland cities, and the drought situation of the three urban agglomerations had a spatial trend of drying from south to north.

\subsubsection{Heat Wave Index}

Figure 5 shows the geographical distribution of the annual average number of heat wave days in the three urban agglomerations from 1981 to 2019. According to the definition of heat waves, the factors influencing the magnitude of the heat wave index include ambient temperature and relative humidity. Summer is the season of the year's highest temperatures; during the day, temperatures rise faster inland than in coastal areas, and the relative humidity is lower. In the Beijing-Tianjin-Hebei and Yangtze River Delta urban agglomerations, the number of heat wave days was higher in the west and lower in the east, while, in the Pearl River Delta region, the number was higher in the north and lower in the south. Therefore, the geographical distribution of heat wave days in the three urban agglomerations was reasonable.
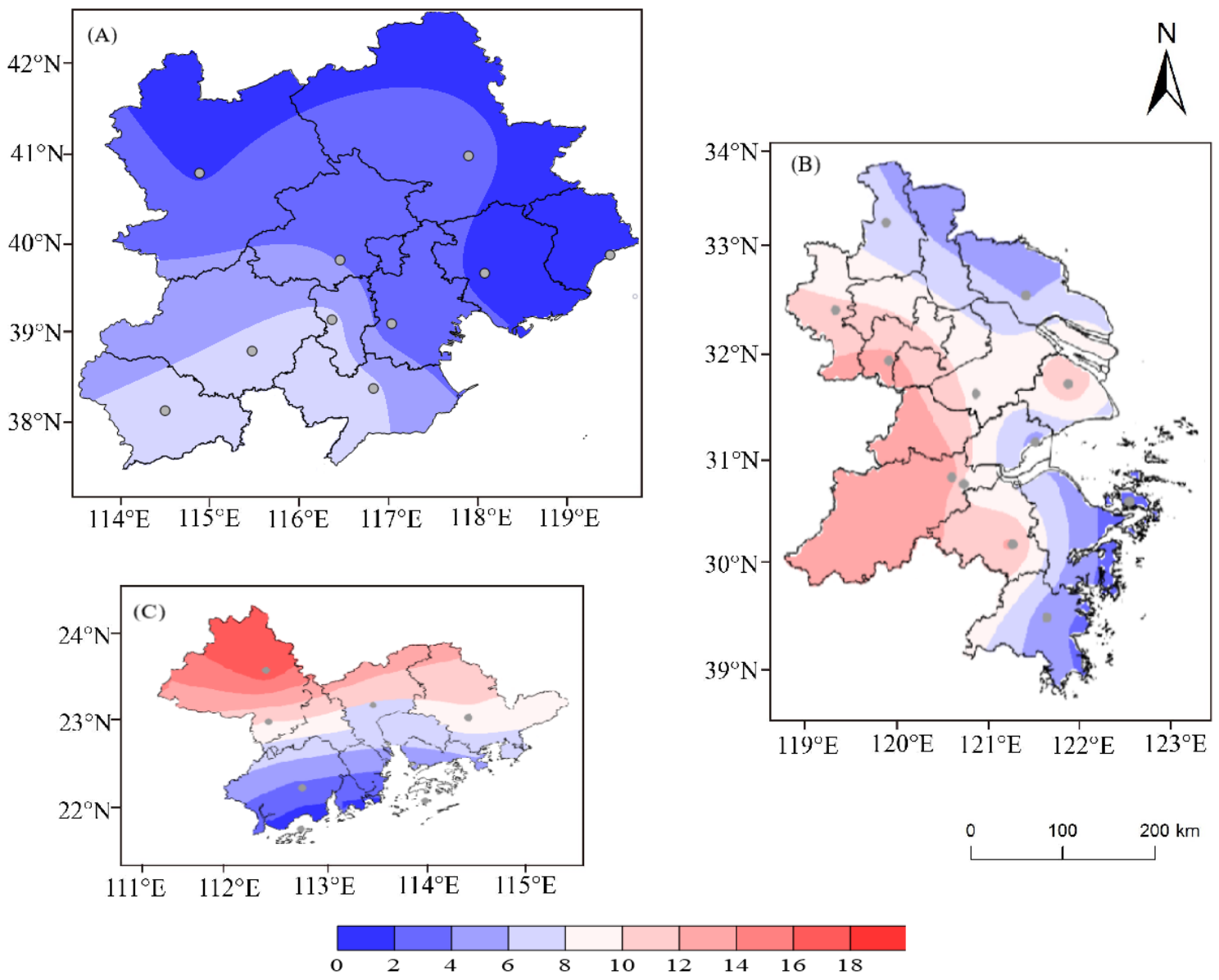

Figure 5. Geographical distribution of annual mean heat wave days in the three urban agglomerations during 1981-2019 (A): Beijing-Tianjin-Hebei; (B): Yangtze River Delta; (C): Pearl River Delta.

In addition, we can also see that the maximum number of heat wave days occurred in Zhaoqing in the Pearl River Delta, and the minimum number was near Qinhuangdao in the Beijing-Tianjin-Hebei area. This is because the Pearl River Delta urban agglomeration is in low latitudes and Zhaoqing is the most interior of the Pearl River Delta cities. During the year, the ambient temperature is higher, and the relative humidity is lower in summer. As a result, the Pearl River Delta had more heat wave days. As Qinhuangdao is located in northern China, the environmental temperature in summer was lower than that in southern 
China. It is also located in the offshore area, which is affected by the sea breeze, and, therefore, Qinhuangdao had lower temperatures and higher ambient humidity. Therefore, Qinhuangdao had the lowest average number of heat wave days. In general, the number of heat wave days in Chinese cities mainly depends on the geographical location, with obvious spatial agglomeration and distribution [33].

\subsubsection{Flood Index}

The annual mean geographical distribution of the flood index in the three urban agglomerations is shown in Figure 6. In the last 39 years, the spatial pattern of precipitation in the Beijing-Tianjin-Hebei urban agglomeration was more in the east and less in the west, which was mainly because of the different terrain features and urban development in the Beijing-Tianjin-Hebei region. Zhangjiakou lies near the Taihang Mountains, a region where descending air and dry adiabatic warming causes the temperature to rise. With less atmospheric moisture and higher temperatures, the flood index near Zhangjiakou was the lowest of the regions studied [34]. The flood index value of the Yangtze River Delta urban agglomeration gradually decreased from south to north because the amount of water vapor brought from the Pacific Ocean was higher in the south, therefore there was more precipitation. The Pearl River Delta urban agglomeration is located in the subtropical monsoon climate zone, and its flood index value was the largest among the three cities, showing a trend of being higher in the south and lower in the north. Precipitation mainly occurs in the westerly belt of the subtropical high and is also affected by weather systems such as typhoons. The region is also affected by the intertropical convergence zone. The Pearl River Delta region thus received the most precipitation [35].
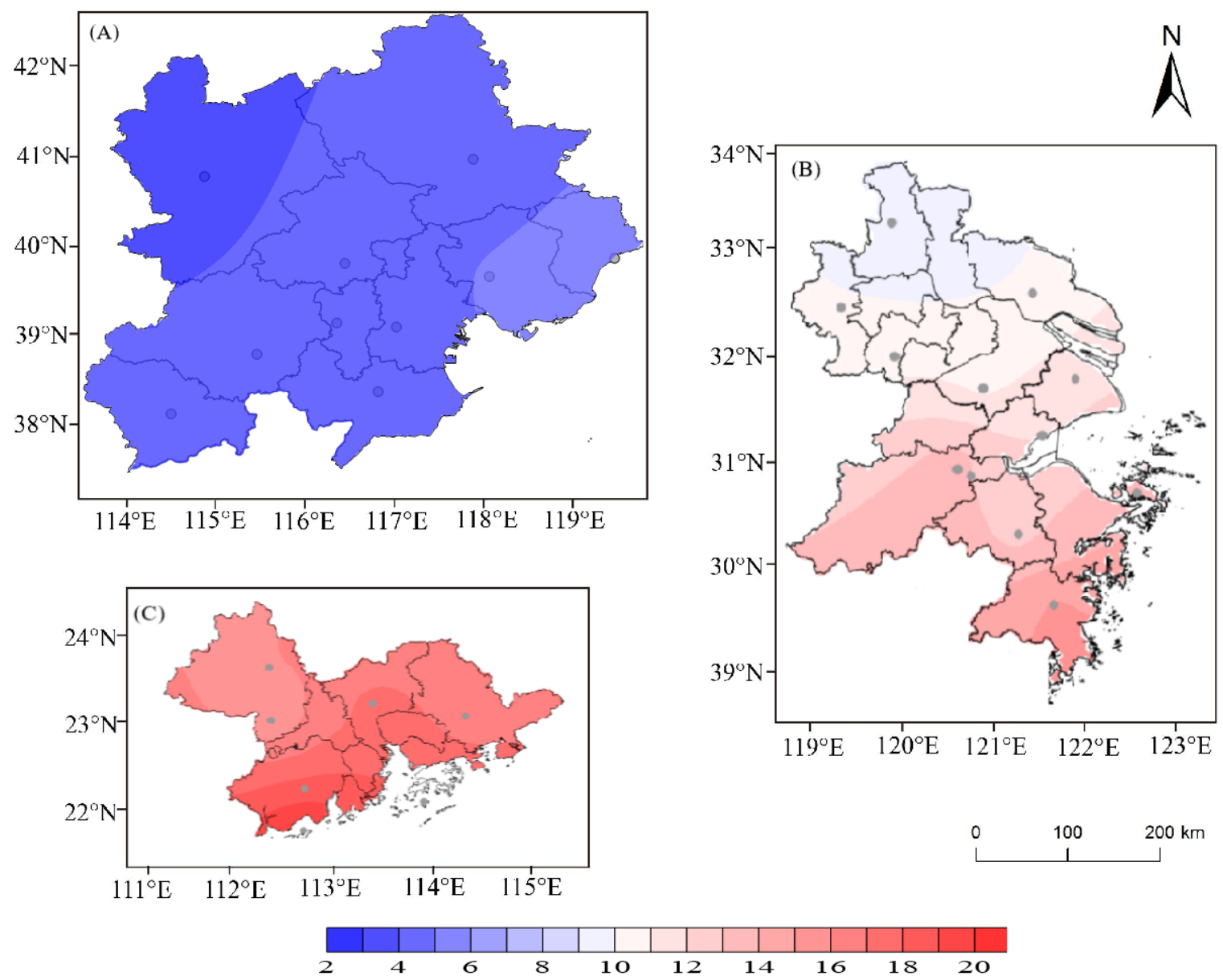

Figure 6. Geographical distribution of the annual mean flood index in the three urban agglomerations (A): Beijing-TianjinHebei; (B): Yangtze River Delta; (C): Pearl River Delta. 


\subsection{Vulnerability Degree of Urban Agglomeration in 2020-2050}

In the context of global warming, extreme meteorological events occur frequently, posing a serious threat to the future and human development. The impact of these meteorological disasters on human beings depends not only on the severity of the disasters themselves but also on social and economic factors such as population and social structure [36]. Therefore, predicting the vulnerability of urban agglomerations during 2020-2050 is crucial to assessing the risk of future climate change.

Based on the Grey model GM $(1,1)$, this paper predicted the population, GDP, and other social and economic factors from 2020 to 2050. We standardized the above data and used the AHP to determine the weight of the five elements in the evaluation of the vulnerability degree of the carrier, including population density, GDP per capita, population urbanization rate, proportion of urban area in total area, and proportion of primary industry in the GDP. The vulnerability of the urban agglomeration in 2020-2050 was calculated, and the spatial description and expression were carried out as shown in Figure 7.

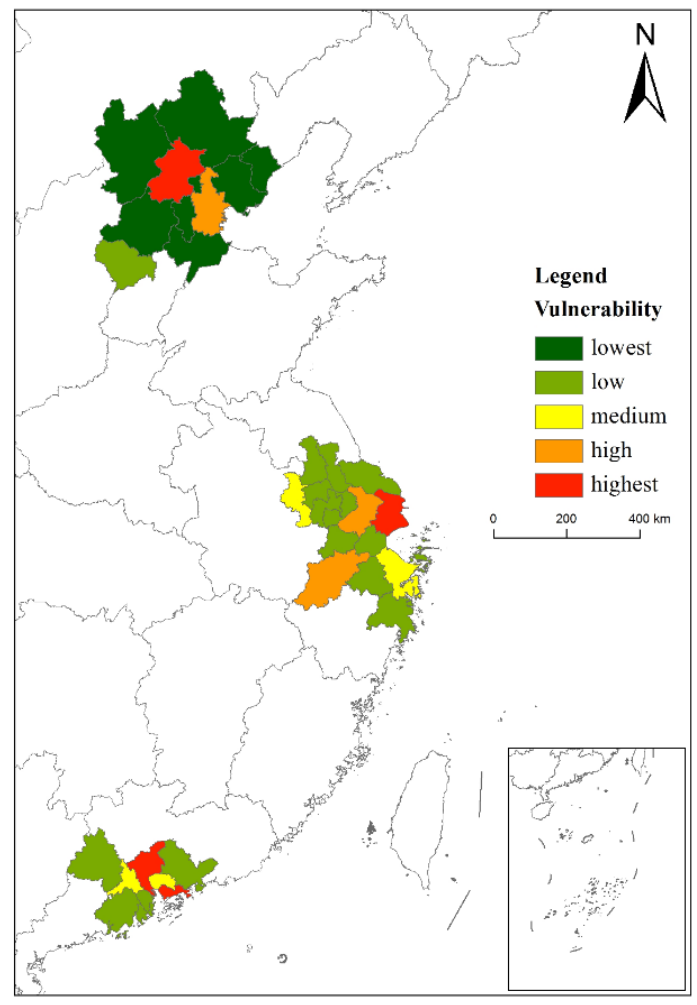

Figure 7. Vulnerability degrees of the three major urban agglomerations during 2020-2050.

Compared with the meteorological disaster risk, which mainly focuses on extreme weather events, the vulnerability degree of urban agglomerations is more concerned with the role of humans and the GDP [37]. In this paper, the vulnerability degree of urban agglomeration refers to the degree to which the social system, with regards to how it is affected by climate pressure, has been damaged because of its own sensitivity and vulnerability. As shown in Figure 6, the high vulnerability of the three urban agglomerations in the future will mainly be concentrated in the new first-tier cities: Beijing in the Beijing-TianjinHebei region, Shanghai in the Yangtze River Delta region, and Shenzhen and Guangzhou in the Pearl River Delta region. With the rapid development of the economy, these cities will bear an increasing population. As the main component of the natural economy, the rapid increase in population increases the vulnerability of cities. In general, the vulnerability of the three major urban agglomerations in the future will mainly be concentrated in the Yangtze River Delta and the Pearl River Delta. In comparison, the future vulnerability of 
the Beijing-Tianjin-Hebei region in China is relatively low, and its resistance to extreme disaster events is stronger.

4.4. Climate Change Hazard in Urban Agglomerations under Different Emission Scenarios during 2020-2050

Based on the climate scenarios of SSP1-2.6, SSP2-4.5, and SSP5-8.5 according to CMIP6 in the near and middle periods (2020-2050), this paper obtained future meteorological elements such as daily mean temperature, daily maximum temperature, daily precipitation, and daily relative humidity under different scenarios. The comprehensive meteorological drought index $(C I)$, heat wave index $(H I)$, and flood index $(F I)$ were calculated to quantitatively evaluate the hazard of climate change in urban agglomerations under different emission scenarios from 2020 to 2050.

Based on the comprehensive meteorological drought index, heat wave index, and flood index, this paper calculated the mild, moderate, and severe occurrence frequencies of drought, heat wave, and extreme flood events. As shown in Table 4, this paper obtained the hazard level of extreme events in different regions based on the method of overlap analysis. Overlap analysis involves the overlay of mild, moderate, and severe drought, heat wave, and flood maps to generate a new data layer with attributes.

Table 4. Extreme event hazard classification index system.

\begin{tabular}{cccc}
\hline Index & Mild & Moderate & Severe \\
\hline CI & $-1.2<\mathrm{CI} \leq-0.6$ & $-1.8<\mathrm{CI} \leq-1.2$ & $\mathrm{CI} \leq-1.8$ \\
HI & $2.8 \leq \mathrm{HI}<6.5$ & $6.5 \leq \mathrm{HI}<10.5$ & $\mathrm{HI} \geq 10.5$ \\
FI & $30 \mathrm{~mm}<\mathrm{FI} \leq 50 \mathrm{~mm}$ & $50 \mathrm{~mm}<\mathrm{FI} \leq 70 \mathrm{~mm}$ & FI $\geq 90 \mathrm{~mm}$ \\
\hline
\end{tabular}

Figure 8 shows the hazards of extreme meteorological events such as drought, heat wave, and flood under different emission scenarios. As seen in Figure $8 \mathrm{~A}-\mathrm{C}$, among the three urban agglomerations, the drought hazard of Beijing-Tianjin-Hebei will be the largest, followed by the Pearl River Delta region, and, finally, the Yangtze River Delta region. The serious drought in the Pearl River Delta is mainly due to the high annual temperature in the Pearl River Delta region and the long-term absence of precipitation in a specific season, which lead to the frequent occurrence of winter and spring drought. At the same time, with the increase in greenhouse gas emission intensity, the drought hazard in Beijing and Tianjin will have an increasing trend. On the one hand, Beijing and Tianjin are located in the North China Plain at high latitudes, which makes it difficult for warm and wet air from the ocean to reach the Beijing-Tianjin-Hebei city region. On the other hand, with the increase in greenhouse gas emissions and the further aggravation of global warming, temperatures in the Beijing-Tianjin-Hebei urban agglomeration are also increasing. In addition, Beijing and Tianjin, as two super large first-tier cities in the Beijing-Tianjin-Hebei urban agglomeration, have obvious urban heat island effects. Therefore, Beijing and Tianjin will have the greatest hazard of drought in the future.

As seen from the middle row (D, E, F) of Figure 8, the hazard of heat waves will be the lowest in the Beijing-Tianjin-Hebei urban agglomeration, followed by the Yangtze River Delta, and the highest in the Pearl River Delta urban agglomeration, from 2020 to 2050. Solar radiation decreases with increasing latitude, therefore the hazard of heat waves will gradually decrease from south to north. However, the hazard of heat waves in some cities in the Yangtze River Delta will also be relatively high because the Yangtze River Delta city cluster is located in the middle and lower reaches of the Yangtze River. In summer, under the subtropical high, atmospheric subsidence prevails and the temperature rises rapidly, forming a summer drought. At the same time, the hazard of heat waves is also relatively high. With the increase in emissions, the heat wave hazard of the three major urban agglomerations on the east coast of China will continue increasing. 

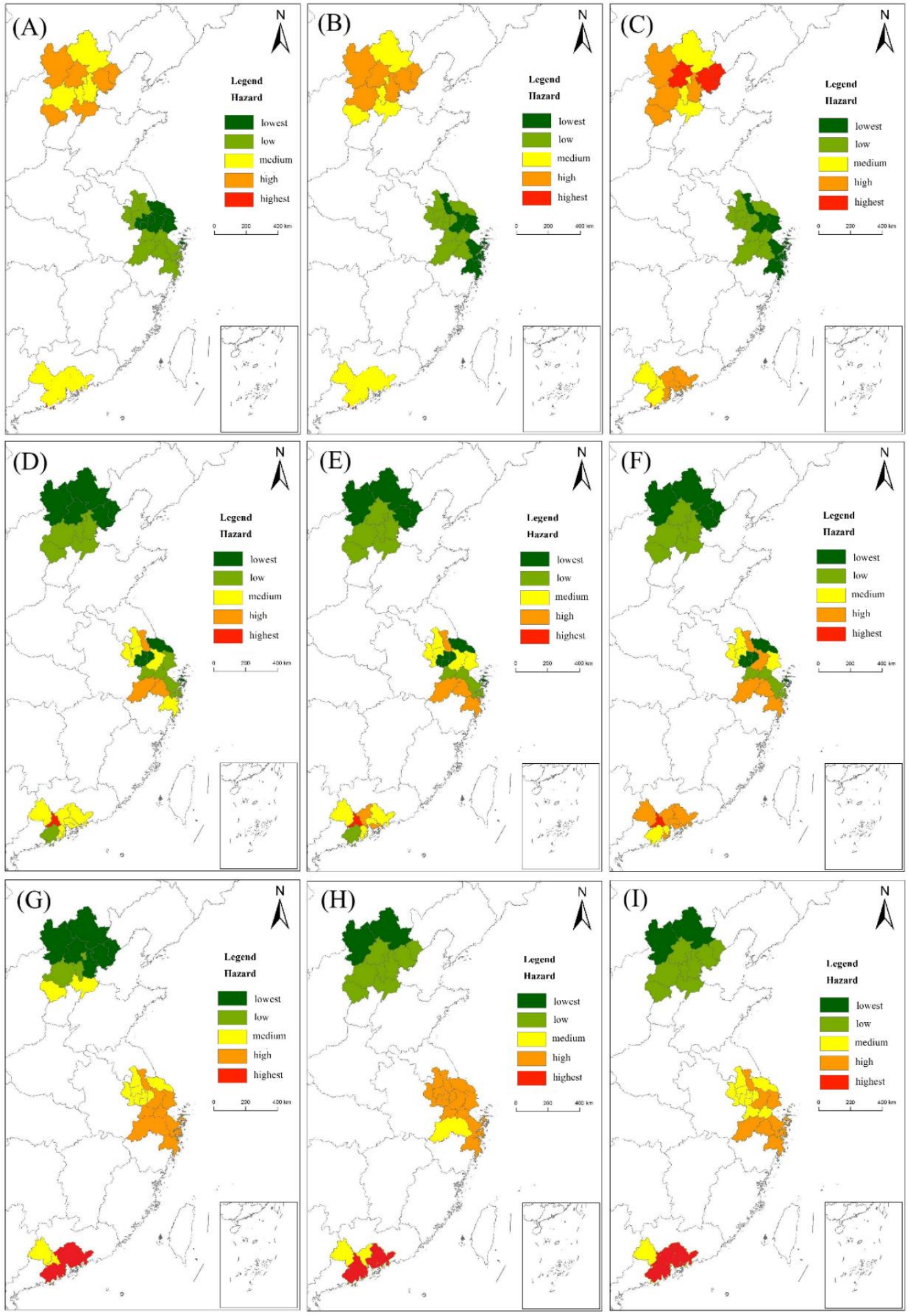

Figure 8. Hazards of drought (A-C), heat wave (D-F), and flood (G-I) in the three urban agglomerations under different emission scenarios: SSP1-2.6 (A,D,G), SSP2-4.5 (B,E,H), and SSP5-8.5 (C,F,I).

From the bottom row (G, H, I) of Figure 8, it can be seen that the flood hazard of the three major urban agglomerations in 2020-2050 will be concentrated in the middle and lower reaches of the Yangtze River. That is, the Yangtze River Delta urban agglomerations will have the greatest flood hazard, while the Pearl River Delta urban agglomerations in 
the low latitudes will have the middle flood hazard, and the Beijing-Tianjin-Hebei region in the middle and high latitudes will have the least flood hazard. The main reason for this is that there are many plains in the middle and lower reaches of the Yangtze River, and the terrain is relatively low and flat. Flooding mainly depends on the precipitation. The Yangtze River Delta urban agglomeration is located in the monsoon climate zone with heavy rain in summer. Huang pointed out that approximately $46 \%$ of the world's regions may suffer from moderate or high hazards of extreme precipitation changes in the future. The frequency of extreme precipitation events will increase under the RCP8.5 scenario, and most regions will show high flood hazards [38]. There was no significant difference in the spatial distribution of flood hazards under the three scenarios analyzed in this paper (SSP1-2.6, SSP2-4.5, and SSP5-8.5); however, with the increase in emission intensity, the disaster hazard of floods increased.

Based on the hazard assessment of drought, heat wave, and flood, and according to the spatial distribution pattern of meteorological disasters, this paper regionalized the hazards of climate change in the three major urban agglomerations in eastern China [39], as shown in Figure 9. It can be seen from the figure that the Pearl River Delta urban agglomeration will experience the greatest hazard of climate change, followed by the Yangtze River Delta, and the Beijing-Tianjin-Hebei urban agglomeration. The hazard of climate change will gradually decrease from south to north. With the increase in emission intensity, the climate change hazard of SSP5-8.5 in the high emission scenario will cause the largest changes.
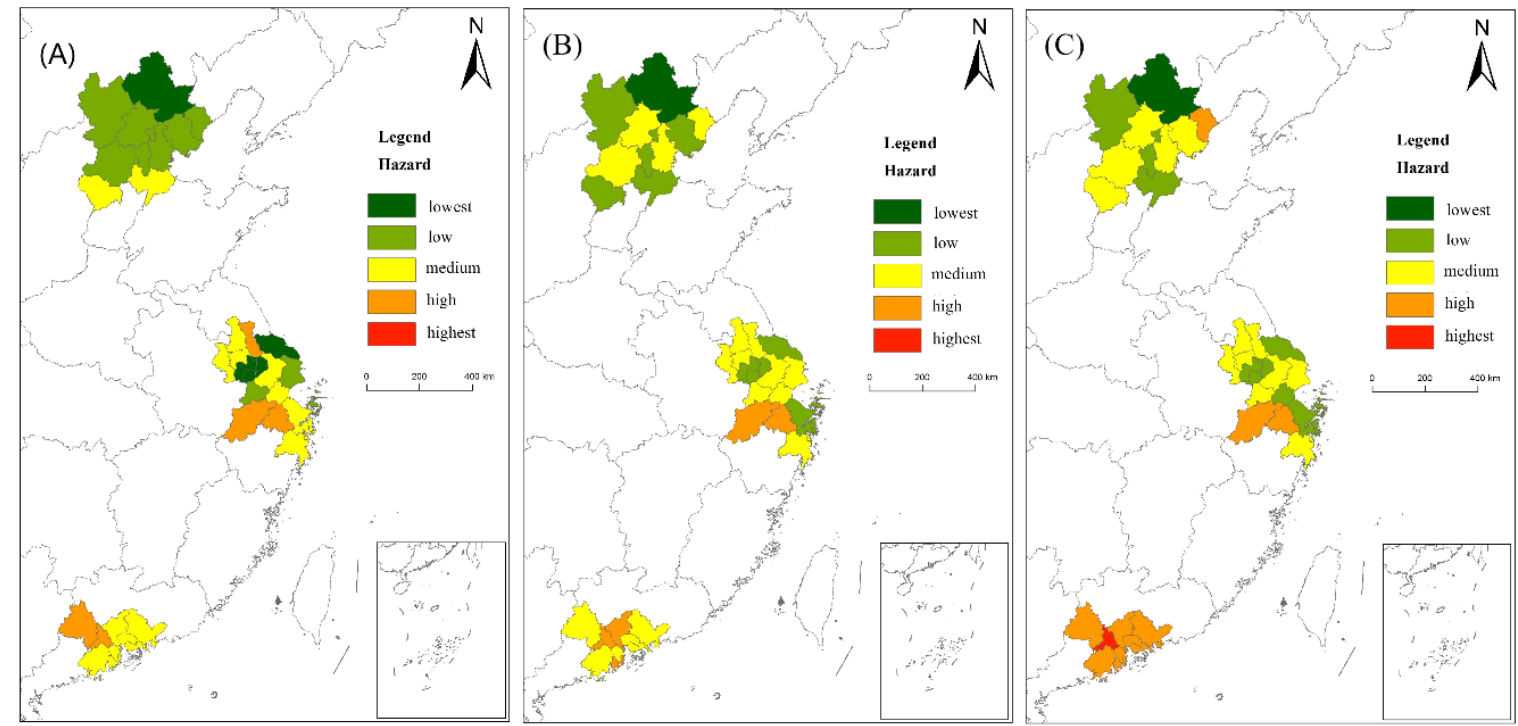

Figure 9. Climate change hazard of the three urban agglomerations under different emission scenarios (A): SSP1-2.6; (B): SSP2-4.5; (C): SSP5-8.5.

\subsection{Climate Change Risk Zoning of Urban Agglomerations under Different Emission Scenarios during 2020-2050}

In this paper, the disaster risk was divided into two parts: the disaster-causing factor and the bearing body. Drought, heat wave, and flood were regarded as disaster-causing factors, and urban agglomerations were regarded as bearing bodies. Disaster risk was equal to the product of disaster risk and the vulnerability of the disaster-bearing body. Therefore, these factores were brought into the climate change risk assessment model to obtain the climate change risk to the three urban agglomerations under different emission scenarios.

Figure 10 shows that the future climate change risk to the Beijing-Tianjin-Hebei urban agglomeration will mainly be concentrated in Beijing and Tianjin, which have higher populations and GDPs. Therefore, when large meteorological disasters occur, these two urban agglomerations will be more vulnerable to risks, while other cities in the BeijingTianjin-Hebei region will show good urban resilience. However, the climate change risk to 
the Yangtze River Delta urban agglomeration will be different, the regional coordination is not consistent and the overall risk will be slightly stronger than that to the Beijing-TianjinHebei urban agglomeration. In addition, the risk of climate change will be high in the Pearl River Delta urban agglomeration, among which Guangzhou and Shenzhen are the cities with the highest risk in the entire Pearl River Delta region. Overall, the higher the emission intensity, the greater the risk of climate change in each urban agglomeration; this conclusion was also consistent with the previous research results $[38,40]$.
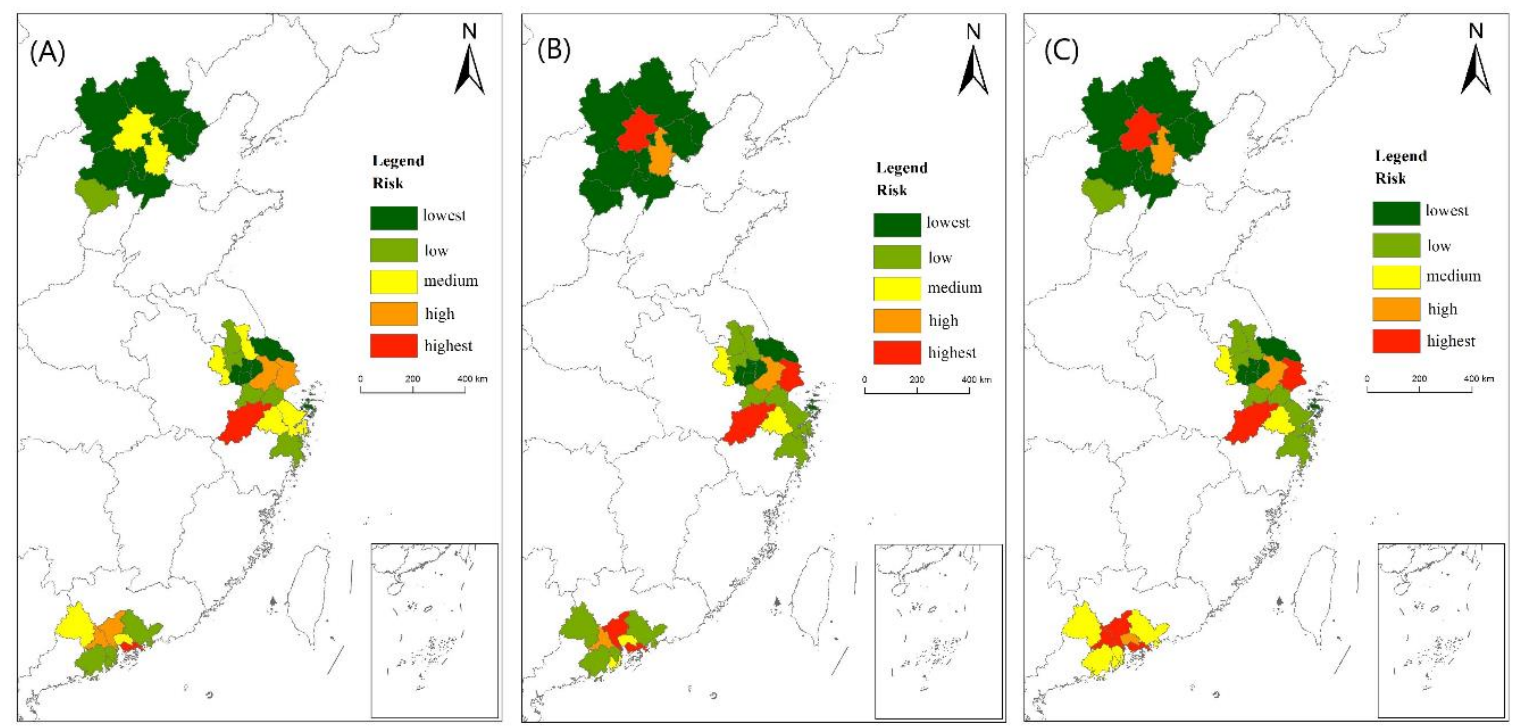

Figure 10. Climate change risks in the three urban agglomerations under different emission scenarios (A): SSP1-2.6; (B): SSP2-4.5; (C): SSP5-8.5.

\section{Conclusions and Discussion}

The risk of climate change to the three major urban agglomerations in eastern China is the result of the combined effects of climate factors and social and economic factors, which need to be cross-analyzed by multiple disciplines and fields. To solve this problem, we selected a climate change risk assessment model as a bridge between natural science analysis and humanistic socioeconomic analysis. The vulnerability degree of urban agglomerations and the hazard of climate change were input into the climate change risk assessment model. Based on the perspective of climate change economics, this paper analyzed the risk of climate change to the three major urban agglomerations in eastern China.

In terms of vulnerability, high vulnerability was mainly concentrated in Beijing, Tianjin, Nanjing, Wuxi, Suzhou, Shanghai, Foshan, Guangzhou, Shenzhen, Dongguan, and other first-tier cities as well as new first-tier cities. These cities tend to be associated with a higher GDP and population, and they are at a higher risk when meteorological disasters strike. On the whole, among the three urban agglomerations, the Yangtze River Delta region was the most vulnerable, followed by the Pearl River Delta region, and the Beijing-Tianjin-Hebei region.

With climate change, drought characteristics in the north and south have changed. In general, the Beijing-Tianjin-Hebei urban agglomeration will have the largest drought hazard in the future, followed by the Pearl River Delta urban agglomeration, and the Yangtze River Delta urban agglomeration. The hazard of heat wave in urban agglomerations in China mainly depends on geographical location, with obvious spatial agglomeration and distribution. The hazard of heat wave gradually decreases from south to north, and the hazard of heat wave in inland cities is higher than that in coastal cities in the same urban agglomerations. In China, future flood hazards will be concentrated in the middle and lower reaches of the Yangtze River; that is, the Yangtze River Delta will have the largest 
flood hazard, the Pearl River Delta the middle flood hazard, and the Beijing-Tianjin-Hebei region the lowest flood hazard.

Among the three coastal urban agglomerations in eastern China, the Pearl River Delta has the highest hazard of climate change, followed by the Yangtze River Delta. The Beijing-Tianjin-Hebei urban agglomeration has the lowest hazard of climate change. The hazard of climate change gradually decreases from south to north. With the increase in emission intensity, the hazard of climate change in the high emission scenario SSP5-8.5 tends to increase.

The risk of future climate change to the Beijing-Tianjin-Hebei urban agglomeration will be mainly concentrated in Beijing and Tianjin, while other cities in the Beijing-TianjinHebei region will show good urban resilience. However, the risk of climate change to the Yangtze River Delta is different, and the regional coordination is not consistent. The overall risk of climate change to the Yangtze River Delta is slightly stronger than that to the Beijing-Tianjin-Hebei urban agglomeration. In addition, the risk of climate change to the Yangtze River Delta urban agglomeration is high overall, among which Guangzhou and Shenzhen are the highest risk cities in the entire Yangtze River Delta region.

Under different emission scenarios, the higher the emission intensity, the greater the future temperature rise, and the greater the risk of climate change that is faced by each urban agglomeration. Therefore, the high incidence of disaster events is closely related to climate warming. Energy saving, emission reduction, low carbon, and environmental protection are effective measures to delay the temperature rise and reduce the frequency of disasters in the future. Therefore, formulating corresponding policies and measures according to the characteristics of climate change in different urban agglomerations is essential to effectively respond to climate change, improve urban resilience, and maintain steady and rapid economic growth.

In the study of the risk of climate change, we only selected three extreme climate events, drought, heat wave, and flood, because they are the most typical and widely distributed meteorological and hydrological events. However, in fact, the risks of climate change are not limited to drought, heat wave, and flood, but also include hail, typhoons, cryogenic freezing, and other disasters. However, the timing and regional nature of these events were more obvious, therefore they were not included in this study. In this paper, five factors: GDP per unit area, the population density, the population urbanization rate, the proportion of urban area in total area, and the proportion of primary industry in the GDP, were considered in the calculation of the vulnerability index of the bearing body, and the semiquantitative method of expert scoring was also used with the AHP method, which may affect the results of risk estimation. In addition, the Grey model is only suitable for medium and short-term prediction, and the accuracy of long-term prediction is limited. In this paper, the climate data of the BCC-CSM2-MR model were selected to predict the future SSP1-2.6, SSP2-4.5, and SSP5-8.5 emission scenarios. Because of the limited space, the multi-model ensemble average requires further study.

Author Contributions: Conceptualization, J.C. and M.S.; Data curation, J.C.; Formal analysis, W.D. and W.Z.; Funding acquisition, J.C.; Investigation, Y.L.; Methodology, M.S.; Project administration, J.L.; Resources, J.Z.; Supervision, M.S.; Validation, J.C., M.S. and W.D.; Writing-original draft, M.S.; Writing-review \& editing, M.S. All authors have read and agreed to the published version of the manuscript.

Funding: This research was funded by the National Key Research and Development Program of China: 2018YFC1509003; National Natural Science Foundation of China: 42075167.

Institutional Review Board Statement: Not applicable.

Informed Consent Statement: Not applicable.

Conflicts of Interest: The authors declare no conflict of interest. 


\section{Appendix A}

Table A1. Experts Scores Technique.

\begin{tabular}{cccccc}
\hline & $\begin{array}{c}\text { Population } \\
\text { Density }\end{array}$ & GDP per Capita & $\begin{array}{c}\text { Population } \\
\text { Urbanization Rate }\end{array}$ & $\begin{array}{c}\text { Proportion of Urban } \\
\text { Area to Total Area }\end{array}$ & $\begin{array}{c}\text { Proportion of Primary } \\
\text { Industry in GDP }\end{array}$ \\
\hline professor A & 5 & 4.3 & 1.7 & 2 & 3 \\
professor B & 5 & 5 & 1.8 & 3 & 2.2 \\
professor C & 5 & 4.8 & 2 & 2.2 & 2.1 \\
professor D & 5 & 4.7 & 2.3 & 1.2 & 2.3 \\
average value & 5 & 4.7 & 1.95 & 2.1 & 2.4 \\
\hline
\end{tabular}

Table A2. Analytic hierarchy Process data.

\begin{tabular}{cccccc}
\hline & $\begin{array}{c}\text { Population } \\
\text { Density }\end{array}$ & $\begin{array}{c}\text { GDP per } \\
\text { Capita }\end{array}$ & $\begin{array}{c}\text { Population } \\
\text { Urbanization } \\
\text { Rate }\end{array}$ & $\begin{array}{c}\text { Proportion of } \\
\text { Urban Area to } \\
\text { Total Area }\end{array}$ & $\begin{array}{c}\text { Proportion of } \\
\text { Primary Industry } \\
\text { in GDP }\end{array}$ \\
\hline Population density & 1 & 1.064 & 2.564 & 2.381 & 2.083 \\
GDP per capita & 0.94 & 1 & 2.41 & 2.238 & 1.958 \\
Population urbanization rate & 0.39 & 0.415 & 1 & 0.929 & 0.813 \\
Proportion of urban area to total area & 0.42 & 0.447 & 1.077 & 1 & 0.875 \\
Proportion of primary industry in GDP & 0.48 & 0.511 & 1.231 & 1.143 & 1 \\
\hline
\end{tabular}

Table A3. Analytic hierarchy Process results.

\begin{tabular}{|c|c|c|c|c|}
\hline Index & Feature Vector & Weight Value & Maximum Eigenvalue & $\mathrm{Ci}$ \\
\hline Population density & 1.548 & $30.960 \%$ & & \\
\hline GDP per capita & 1.455 & $29.102 \%$ & & \\
\hline Population urbanization rate & 0.604 & $12.074 \%$ & 5 & 0 \\
\hline Proportion of urban area to total area & 0.65 & $13.003 \%$ & & \\
\hline Proportion of primary industry in GDP & 0.743 & $14.861 \%$ & & \\
\hline
\end{tabular}

Table A4. Random consistency table.

\begin{tabular}{cccccccccc}
\hline $\mathbf{n}$ & $\mathbf{3}$ & $\mathbf{4}$ & $\mathbf{5}$ & $\mathbf{6}$ & $\mathbf{7}$ & $\mathbf{8}$ & $\mathbf{9}$ & $\mathbf{1 0}$ \\
\hline $\mathrm{R}$ & 0.52 & 0.89 & 1.12 & 1.26 & 1.36 & 1.41 & 1.46 & 1.49 \\
\hline
\end{tabular}

\section{References}

1. Sun, W.; Li, Q.; Huang, B.; Cheng, J.; Song, Z.; Li, H.; Dong, W.; Zhai, P.; Jones, P. The Assessment of Global Surface Temperature Change from 1850s: The C-LSAT2. 0 Ensemble and the CMST-Interim Datasets. Adv. Atmos. Sci. 2021, 38, 875-888. [CrossRef]

2. Field, C.B.; Barros, V.R.; Dokken, D.J.; Mach, K.J.; Mastrandea, M.D.; Bilir, T.E.; Chatterjee Ebi, K.L.; Estrada, Y.O.; Genova, R.C. (Eds.) Climate Change 2014: Impacts, Adaptation, and Vulnerability; Cambridge University Press: Cambridge, UK, 2014.

3. Liu, D.; Wang, D.; Wu, J.; Wang, Y.; Wang, L.; Zou, X.; Chen, Y.; Chen, X. A risk assessment method based on RBF artificial neural network-cloud model for urban water hazard. J. Intell. Fuzzy Syst. 2014, 27, 2409-2416. [CrossRef]

4. Yang, Y.; Peng, H. Assessment of waterlogging risk for urban drainage system. J. Water Purif. Technol. 2018, 37, 116-121. (In Chinese) [CrossRef]

5. Liu, X.; Qu, J.; Liu, L.; Li, H.; Pei, H.; Ceng, J. Research on the Assessment of Urban Climate Change Adaptation Capability in Western China. J. Ecol Econ. 2019, 35, 104-110. Available online: https:/ / core.ac.uk/download/pdf/222802639.pdf (accessed on 18 October 2021). (In Chinese)

6. Giupponi, C.; Mojtahed, V.; Gain, A.K.; Biscaro, C.; Balbi, S. Integrated risk assessment of water-related disasters. In HydroMeteorological Hazards, Risks and Disasters; Academic Press: Cambridge, MA, USA, 2014; pp. 163-200.

7. Wu, S.; Gao, J.; Deng, H.; Liu, L.; Pan, T. Climate change risk and methodology for its quantitative assessment. J. Prog. Geogr. 2018, 37, 28-35.

8. Sahana, V.; Mondal, A.; Sreekumar, P. Drought vulnerability and risk assessment in India: Sensitivity analysis and comparison of aggregation techniques. J. Environ. Manag. 2021, 299, 113689. [CrossRef] 
9. Dong, S.; Tao, S.; Yang, W.; Li, Z.; Li, Y. Impacts of climate change on urban agglomeration in central and western regions of China. J. Arid Environ. 2011, 25, 72-76.

10. Apel, H.; Aronica, G.T.; Kreibich, H.; Thieken, A.H. Flood risk analyses-How detailed do we need to be? Nat. Hazards 2009, 49, 79-98. [CrossRef]

11. Barbier, E.B. A global strategy for protecting vulnerable coastal populations. J. Sci. 2014, 345, 1250-1251. [CrossRef]

12. Hay, C.C.; Morrow, E.; Kopp, R.E.; Mitrovica, J.X. Probabilistic reanalysis of twentieth-century sea-level rise. J. Nat. 2015, 517, 481-484. [CrossRef]

13. Sun, S.; Zhai, J.; Li, Y.; Huang, D.; Wang, G. Urban waterlogging risk assessment in well-developed region of Eastern China. J. Phys. Chem. Earth 2020, 115, 102824. [CrossRef]

14. Arnell, N.W.; Lowe, J.A.; Challinor, A.J.; Osborn, T.J. Global and regional impacts of climate change at different levels of global temperature increase. J. Clim. Chang. 2019, 155, 377-391. [CrossRef]

15. Alexander, K.; Hettiarachchi, S.; Ou, Y.; Sharma, A. Can integrated green spaces and storage facilities absorb the increased risk of flooding due to climate change in developed urban environments? J. Hydrol. 2019, 579, 124201. [CrossRef]

16. Zhang, X.; Zhou, J.; Song, W. Simulating urban sprawl in china based on the artificial neural network-cellular automata-Markov model. J. Sustain. 2020, 12, 4341. [CrossRef]

17. Wang, C.; Meng, Q. Research on the sustainable synergetic development of Chinese urban economies in the context of a study of industrial agglomeration. J. Sustain. 2020, 12, 1122. [CrossRef]

18. Chou, J.; Sun, M.; Xu, Y.; Yang, F.; Li, J.; Zhao, W. Resilience of Grain Yield in China Under Climate Change Scenarios. J. Front. Environ. Sci. 2021, 9, 44. [CrossRef]

19. Deng, J. Introduction to grey system theory. J. Grey Syst. 1989, 1, 1-24.

20. Sun, M.; Chou, J.; Xu, Y.; Yang, F.; Li, J. Study on the thresholds of grain production risk from climate change in China's main grain-producing areas. J. Phys. Chem. Earth. 2020, 116, 102837. [CrossRef]

21. Yin, M. Fifteen years of grey system theory research: A historical review and bibliometric analysis. J. Expert Syst. Appl. 2013, 40, 2767-2775. [CrossRef]

22. Huang, C.; Yin, J.; Zhang, J. Calculation of Risk Assessment Index Weight by Analytic Hierarchy Process. J. China Public Secur. 2018, 19-22. (In Chinese) [CrossRef]

23. Tan, R.R.; Aviso, K.B.; Huelgas, A.P.; Promentilla MA, B. Fuzzy AHP approach to selection problems in process engineering involving quantitative and qualitative aspects. J. Process. Saf. Environ. Prot. 2014, 92, 467-475. [CrossRef]

24. Chen, D.; Da, L.; Yan, W.; Deng, D.; He, L.; Wu, S.; Yu, L.; Yang, J.; Wang, J.; Zhang, L. Screening and Evaluation of Suitable Shrubs for Sand Control in Alpine Sandy Land of Northwest Sichuan Based on AHP Analysis. J. Sichuan For. Sci. Technol. 2021, 42, 65-69.

25. GB/T 20481-2017, Grades of Meteorological Drought. Available online: https://kns.cnki.net/kcms/detail/detail.aspx? FileName=SCSF00050541\&DbName=SCSF (accessed on 12 November 2021).

26. He, J.; Yang, X.; Li, J.; Jin, J.; Wei, Y.; Chen, X. Spatiotemporal variation of meteorological droughts based on the daily comprehensive drought index in the Haihe River basin, China. Nat. Hazards 2015, 75, 199-217. [CrossRef]

27. Ma, J.; Zhang, L.; Li, J. Automatic Calculation of Comprehensive Meteorological Drought Index (Ic). J. Meteorol. Res. Appl. 2011, 32,17-19. Available online: http:/ / www.cqvip.com/qk/96341a/201104/40486752.html (accessed on 12 November 2021). (In Chinese)

28. GB/T 29457-2012, Grade of the heat wave. Available online: https://kns.cnki.net/kcms/detail/detail.aspx?FileName=SCSF000 39877\&DbName $=$ SCSF (accessed on 20 November 2021).

29. Zhou, Y.; Zhu, S.; Hua, J.; Li, Y.; Xiang, J.; Ding, W. Spatio-temporal distribution of high temperature heat wave in Nanjing. J. Geogr. Inf. Sci. 2018, 20, 1613-1621. Available online: http://www.cqvip.com/qk/86408a/201811/676778597.html (accessed on 18 October 2021). (In Chinese)

30. Huang, C. Basic principles of natural disaster risk analysis. J. Nat. Disasters 1999, 21-30. Available online: http:/ /www.cqvip. com/qk/97398x/199902/3579615.html (accessed on 18 October 2021).

31. Chou, J.; Ban, J.; Dong, W.; Hu, C.; Dai, R. Characteristics analysis and assessment of economic damages caused by tropical cyclones in Guangdong Province. Chin. J. Atmos. Sci. 2018, 42, 357-366. (In Chinese) [CrossRef]

32. Miao, Z.; Xu, L.; Lu, M. Analysis of Drought Characters Based on SPEI Index in Beijing-Tianjin-Hebei Region. J. Yellow River 2018, 40, 51-57. (In Chinese) [CrossRef]

33. Huang, X.; Wang, B.; Guo, Y.; Li, Y. Characteristics of urban extreme heat and assessment of social vulnerability in China. J. Geogr. Res. 2020, 39, 1534-1547. (In Chinese) [CrossRef]

34. Lu, J.; Liu, J.; Liu, M.; Cao, Y.; Li, H.; Ning, Y. Multi-scale analysis of precipitation in the Beijing-Tianjin-Hebei urban agglomeration in the past 55 years. Hydro Sci. Eng. 2020, 6, 23-31. (In Chinese) [CrossRef]

35. Huang, G.; Chen, Y.; Yao, Z. Spatial and temporal evolution characteristics of extreme rainfall in the Pearl River Delta under high urbanization. Adv. Water Sci. 2021, 32, 161-170.

36. Roper, R.E. Book Review of "Heat Wave: A Social Autopsy of Disaster in Chicago". Homel. Secur. Emerg. Manag. 2011, 1. [CrossRef]

37. Huang, J.; Su, F. The Review and Prospect on the Hot Issues of Urban Social Vulnerability to Disasters. Sci. Geol. Sin. 2017, 37, 1211-1217. 
38. Huang, H.; Cui, H.; Ge, Q. Assessment of potential risks induced by increasing extreme precipitation under climate change. Nat. Hazards 2021, 108, 2059-2079. [CrossRef]

39. Wu, S.; Pan, T.; Liu, Y.; Deng, H.; Jiao, K.; Lu, Q.; Feng, A.; Yue, X.; Yin, Y.; Zhao, D.; et al. Comprehensive climate change risk regionalization of China. Acta Geogr. Sin. 2017, 72, 3-17.

40. Dong, S.; Xu, Y.; Zhou, B.; Hou, M.; Li, R.; Li, Y.; Zhang, Y. Projected risk of extreme heat in China based on CMIP5 models. Adv. Clim. Chang. Res. 2014, 10, 365. 